\title{
Arbor
}

\section{Cognición y Retórica}

\section{Marco Antonio Coronel Ramos, Rosa Giménez Moreno}

Arbor CLXVII, 697 (Enero 2004), 41-58 pp.

Pocos términos existen tan mudables en la cultura occidental como el de retórica. Se le define como arte de la persuasión, como teoría de la argumentación o incluso como ciencia literaria. Todas estas perspectivas tienen un denominador común: entienden los tropos y figuras retóricas como instrumentos comunicativos y literarios. Sin obviar estos desarrollos de la retórica, los autores de este trabajo tratan de discernir los aspectos cognitivos rastreables en la retórica clásica $y$, al tiempo, ofrecer un acercamiento a lo que sería una retórica cognitiva, basada en el presupuesto de que tropos y figuras son redes conceptuales que estructuran el pensamiento humano.

En consecuencia, en este artículo se pasa revista al sustrato cognitivo implícito en la retórica clásica y se explicita, sintéticamente, los hitos fundamentales en la evolución del pensamiento lingüistico occidental, rastreando en ellos los aspectos calificables lato sensu de cognitivos. Se llega así a la lingüistica cognitiva, cuyo postulado básico es la metaforicidad del lenguaje humano. Los autores del trabajo amplian los limites de esta afirmación para sostener que en general todos los tropos y figuras pueden describir los procesos mentales y emotivos humanos.

\section{La Retórica en el Ágora}

Nacida como arte de argumentar en el seno de una sociedad abocada social y políticamente al ágora, la retórica fue el origen de una serie de reflexiones sobre el lenguaje y, en particular, sobre el modo en que el len- 
guaje representa -o configura- la realidad. Su soporte es la transformación del concepto de justicia que se opera en Grecia; su raíz, las implicaciones que esta transformación ejerce sobre la percepción intelectual y emocional de nociones como verdad, ciudadanía, legalidad o gobierno.

Por otro lado, transformada en sistema discursivo, la retórica se erige en seña de identidad de la nueva sociedad. Por así decir, se convirtió en el sustento dialéctico de la sociedad democrática ateniense. La razón de este proceso hay que buscarla en el propio sistema democrático, ya que, en él, las ideas quedan a merced de los matices: el debate y la persuasión son inherentes a la democracia, de ahí que pueda aseverarse que la retórica es el producto más característico de la sociedad democrática ateniense y, valga la expresión, el telón que cegó la caverna platónica, velando la perspicuidad de lo cierto y lo verdadero con la luz de lo posible y lo verosímil.

Se diría que, si la democracia es el ámbito de lo posible y de lo verosímil, la retórica se configura como sistematización de esos dos ámbitos. No puede ser de otro modo porque, en tal sociedad, los conceptos no pueden permanecer ajenos a la percepción de quien los usa, ni los valores, alienados de la opinión y de la diacronía histórica que los modela. La democracia, en cierto modo, permite dar voz a todos, pero esa virtualidad origina una gran ambivalencia en la percepción de la realidad y los propios valores.

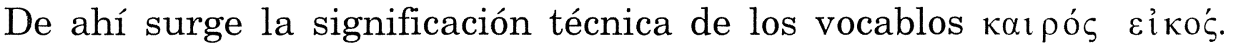
Kaı pós alude a lo contextual, a lo pragmático, en definitiva, a la ocasión como elemento formador de un discurso; ci кo'́, a lo posible, a lo verosímil, a las apariencias de verdad. La conceptualización de la realidad de las cosas - del mundo- dependerá, pues, de la función que una sociedad determinada les otorgue y del uso que haga de ella. Estos conceptos sólo pueden surgir en el seno de una sociedad que tenga al debate como sustento de las relaciones sociales y políticas. Los valores estarán sujetos, entonces, a las tensiones polémicas y a las distensiones consensuales. La retórica será la estructura articuladora de dicho debate y, como tal, el armazón de polémicas y asensos.

\section{El Aristócrata Debelador de la Retórica}

Por su origen democrático y por el relativismo que impone a los valores, Platón rechaza la retórica ${ }^{1}$. Platón no se interesa por el uso del lenguaje, sino por la ontología de las cosas, por la verdad del lenguaje. Se preocupa de que el hilo que une la palabra y el referente no distorsione 


\section{Cognición y Retórica}

una verdad que, a su juicio, no puede estar sujeta al contexto y a lo opinable. Platón, en definitiva, no toma en consideración las tensiones pragmáticas que las ideas establecen entre sí, de ahí que tampoco atienda a las palabras en tanto que éstas son testigos del devenir sinuoso y metafórico - pero nunca impreciso ni titubeante- del pensamiento humano ${ }^{2}$.

Ni impreciso ni titubeante podía ser para él el pensamiento humano, sustentado en la suerte de universales que denominó ideas. Ésta fue su gran -y tal vez inconsciente- aportación a una eventual retórica cognitiva. Frente a él, los sofistas -pragmatistas avant la lettre-inauguran un modelo de educación cuyo objetivo esencial es formar a los ciudadanos a moverse por los entresijos socio-políticos de la ciudad, manejando los hilos de la ocasión y la ambivalencia de los conceptos. Razón, praxis política y ética quedan así entrelazadas en un conjunto de estrategias discursivas.

A partir de aquí el debate sobre la retórica se centrará, por un lado, en la explicitación y casuística de esas estrategias discursivas y, por el otro, en cómo conciliar la verdad y la opinión, la filosofía y la propia retórica -el pensamiento y la comunicación-. Ejemplo de lo segundo es Isócrates, que defiende la retórica como saber ineludible para el ciudadano: favorece su ubicación como sujeto activo de la ciudad. Su función no sería contradictoria con la búsqueda de la verdad ni de la virtud, porque su cometido es otro: promocionar y celebrar la democracia. Desde esta perspectiva, la retórica construye ideológicamente la ciudad ${ }^{3}$, porque, si el hombre se define por su capacidad de hablar, la civilización lo haría por su utilización de esta facultad definitoria del hombre ${ }^{4}$. Genera el concepto mismo de ciudad requerido por la evolución histórico-política de la sociedad del momento.

Estas discusiones tendrán como resultado la transformación de la retórica en una ciencia sobre el lenguaje artístico, abandonándose en parte otras potenciales sendas como la de haber devenido teoría del conocimiento, teoría sobre cómo el lenguaje refleja -y mediatiza- la realidad. Así, un autor como Cicerón especulará sobre la retórica en la idea de que es una técnica para argumentar y convencer con la palabra y, al tiempo, para contrarrestar las objeciones de los que veían en esa técnica un campo abonado para demagogos, engatusadores y mentirosos, afirma que el orador perfecto no requiere sólo maestría en las técnicas retóricas, sino también conocimiento real de las cosas, o lo que es lo mismo, conocimiento de la filosofía - cosa que parece concesión a las censuras de Platón- ${ }^{5}$. Quedan con ello armonizadas la necesidad socio-política de la oratoria con el ideal platónico de verdad filosófica. 


\section{Aspectos Cognitivos de la Retórica Clásica}

Dada la trayectoria mencionada de la retórica, es ciertamente arriesgado hablar de aspectos cognitivos en la retórica clásica. Esta expresión sólo parece ajustada si se elucida la retórica no sólo como instrumento para conseguir influencia y ascendencia públicas, sino como una insoslayable consecuencia de la naturaleza humana. Esta idea está presente de un modo sistemático en Aristóteles, cuando el Estagirita detalla la retórica como práctica comunicativa social y política, sin enfrentarla al concepto ontológico -y platónico- de verdad ${ }^{6}$. Se preguntará entonces por los procesos lógico-semánticos, partiendo de la idea de que retórica y dialéctica van a la par: ambas ciencias tratan de las opiniones comunes, de los argumentos probables y de las materias generales ${ }^{7}$. La diferencia entre ellas estriba en que la dialéctica usa la deducción lógica, mientras que la retórica se sirve de los argumentos probables y verosímiles.

La retórica, en definitiva, es producto de una definición del hombre como ser social ${ }^{8}$, hecho que lleva implícito una descripción social y pragmática del lenguaje -y del conocimiento humano-. Este postulado que vincula la retórica con la cognición se explicita, en cierta manera, en dos nociones que Aristóteles desarrolla:

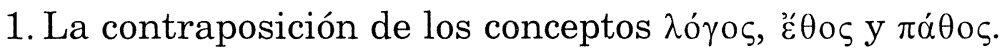

2. La creencia de que la retórica sistematiza una cualidad humana innata.

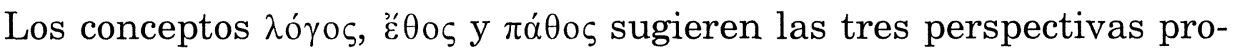
batorias que se puede adoptar en un discurso: la de la argumentación

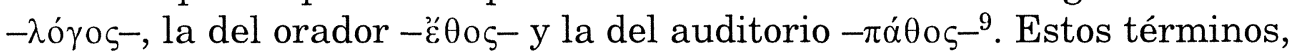
más allá de otras consideraciones, sitúan el discurso en el tiempo y el espacio de los comunicantes y en el conjunto de convicciones que amalgama una sociedad y bosquejan la ética, la retórica y la política como cañamazo de la vida ciudadana. En efecto, describen la comunicación como fruto de juicios y emociones nacidos de la gnoseología humana y asentados pragmáticamente en los idearios socio-culturales que definen toda civilización. La retórica sería, dentro de este razonamiento, una suerte de sistematización de los procedimientos que hacen comunicable la realidad intelectual y emotiva del hombre ya sea desde la coherencia social del lenguaje $-\lambda o ́ \gamma \circ \varsigma-$, desde la capacidad creativo-especulativa de los hablantes $-\ddot{\varepsilon} \theta 0 \varsigma-$ o desde las respuestas significantes de los oyentes $-\pi \dot{\alpha} \theta$ os-.

También fue de gran trascendencia la idea de que la retórica sistematiza una cualidad innata en el hombre: la cualidad de hablar. La im- 


\section{Cognición y Retórica}

portancia de esta idea hay que relacionarla con el axioma de que la capacidad de hablar hizo posible la civilización ${ }^{10}$, ya que sólo el lenguaje es percibido como origen y garante del mantenimiento del progreso y la paz sociales ${ }^{11}$. El idioma es, además, el vínculo fundamental que cohesiona la sociedad. En este sentido, la retórica no sería más que la sistematización del lenguaje habitual y podría esclarecer la manera en que el hombre piensa y se comunica. Tal vez por ello, el citado Cicerón pudo calificar de elocuentes a personajes como Ulises que vivieron antes de la aparición de la técnica retórica ${ }^{12}$. Por la misma razón afirmaría que la elocuencia no surge del artificio, sino el artificio de la elocuencia ${ }^{13}$.

\section{La Retórica Clásica y el Lenguaje}

No serán éstas, como ya se ha dicho, las sendas habituales holladas en los tratados clásicos de retórica. Lo que empieza siendo -sobre todo desde Aristóteles- análisis de la argumentación y de la génesis del pensamiento, ordenado, en cierta medida, en la parte de la retórica denominada inventio, se convierte en reflexión sobre el lenguaje artístico y, en un momento posterior, en ensayo de estilística. Esta evolución no es ajena al colapso de las democracias griegas. En este sentido, si la democracia impuso la necesidad de sistematizar los aspectos persuasivos del discurso y del debate, su crisis convirtió aquellas cavilaciones en investigación estilística. De este modo se desvanecen también las tendencias cognoscitivas apuntadas en los tratados retóricos clásicos. La retórica ya no será necesaria para facilitar al ciudadano su integración en la vida pública, sino para dotarlo de la erudición que su sociedad reclama de los hombres cultos $^{14}$.

Prueba de este tránsito son los tratados de estilística de Dionisio de Halicarnaso o el Sobre lo Sublime de Pseudo-Longino. Sin embargo, es en Quintiliano en donde se hace más evidente esta evolución, ya que este preceptor romano conjugará en una misma obra el estudio de la retórica con el de la pedagogía y la crítica literaria ${ }^{15}$. Este hecho sólo es explicable desde una retórica literaria convertida en método no de argumentar, sino de explicar lo literario. Quintiliano, en concreto, teoriza sobre los mejores métodos de enseñanza y sobre cómo hacer de los alumnos hombres cultos por vía de la imitación literaria. No explica cómo elaborar pensamientos, ni menos aún cómo piensa el hombre, es decir, no trata de los procesos cognitivos que intervienen en el aprendizaje humano, sino de cómo debe hablar el hombre erudito y culto. De ahí su insistencia en el esfuerzo requerido para esta misión ${ }^{16}$ : cuesta trabajo y exige mucho ejercicio apren- 
der retórica porque no es un adiestramiento para pensar o sentir -cosa natural en el hombre-, sino que es pura formación literaria ${ }^{17}$.

Los romanos eran conscientes de esta mudanza como lo demuestra las críticas de Tácito contra una retórica escolar declamatoria ${ }^{18}$ en la que primaba la elocutio frente a una inventio resolutiva ${ }^{19}$. Parece preferir entonces la retórica más argumental -aristotélica-, que habría perecido, según su juicio, ante la corrupción política y moral de Roma ${ }^{20}$. Volvemos así al principio de este trabajo: la sistematización retórica como conjunto de estrategias argumentales surge de la libertad democrática ${ }^{21}$.

\section{La Retórica Occidental}

La retórica escolar romana ha pervivido en Occidente convertida en lo que podemos denominar retórica elocutiva, una de cuyas partes es la tropología. Podría decirse que la retórica clásica se fraccionó en dos partes: una teoría de la argumentación, que quedará fusionada con la lógica y la dialéctica, y una teoría de los tropos y figuras, que dará origen a la estilística. Desde entonces quedarán en Occidente plenamente asentadas premisas como la existencia de un lenguaje recto, ajeno a los tropos y figuras, y la definición de tropo como desvío del término propio sólo justificable por razones estéticas o de la persuasión retórica.

Todo ello se pone de manifiesto si se tiene presente la distinción habitual entre gramática y retórica: la gramática enseña a hablar; la retórica, las reglas del discurso persuasivo ${ }^{22}$-o literario-. Gramática y retórica colisionan cuando la persuasión exija ir más allá de los límites gramaticales. Es en este sentido, los tropos son definidos como procedimientos por los que, en determinadas circunstancias y por razones concretas, una palabra asume un sentido distinto del que le sería propio.

Pocas veces hasta el siglo XIX se matizaron estas palabras. Muy interesante a este respecto es la apreciación que C. C. du Marsais incluye en su Traité des Tropes en la línea de que se oyen más figuras literarias en el mercado que en los centros académicos ${ }^{23}$. De este modo se empieza a poner de manifiesto que lo literario no nace por oposición -ni como transgresiónde lo cotidiano. Consecuencia semejante puede extraerse de la imagen de la lengua como energía acuñada por W. von Humboldt, porque con ella el significado de las palabras dependerá en mayor o menor medida de su uso y de su función dentro del espejo cultural que cada lengua representa ${ }^{24}$.

Inspirado tal vez en Humboldt, Alfred Biese explicará, a finales del siglo XIX, que las metáforas son expresiones que ensanchan el universo humano. La metaforización sería el proceso normal por el que el hombre 


\section{Cognición y Retórica}

evoluciona conceptualmente ${ }^{25}$. Algo semejante parece pensar A. Nietzsche, al decir, que la metáfora es propia de la experiencia cognoscitiva humana. A su juicio, el concepto es siempre el resultado de una doble metáfora: la que conduce de los impulsos nerviosos a las imágenes y la que transforma la imagen en sonido ${ }^{26}$. De esta manera la metáfora se convierte en el sendero que conduce al hombre desde sus sensaciones a sus verbalizaciones.

Se diría que la metáfora es el proceso por el que el hombre hace inteligible su mundo. Es la materia prima de la inteligencia. Así, E. Cassirer sostendrá que el habla nace en el ser humano desde lo cognitivo y lo emotivo y que la metáfora se encuentra ya en el mismo momento del nacimiento del habla ${ }^{27}$. Por ello, quizá, criticara B. Croce la suposición de la existencia de un término propio frente al tropo. Manifestará que las cosas siempre se denominan según su término propio ${ }^{28}$.

En cierto modo estas ideas estaban ya presentes en Aristóteles para el que la metáfora pone al hombre en contacto con lo desconocido: en concreto, la metáfora abre al hombre los caminos del conocimiento de lo desconocido $^{29}$. Sin embargo, la tradición, como se ha indicado, no prestó atención a estas posibles derivaciones de la retórica clásica, obviando los elementos gnoseológicos de tropos y figuras. El interés se focalizó en su uso poético, también establecido por el propio Aristóteles.

Así se observa en los lingüistas estructuralistas ${ }^{30}$. En ellos resulta especialmente interesante el tratamiento de la metáfora, condicionado por conceptos heredados del siglo XIX como el de metaforización. De este modo, focalizan sus investigaciones más que en la metáfora en sí -inasible para su pretensión de analizar el lenguaje científicamente- en el proceso de substitución del lexema propio por el tropo. Estos lingüistas se mantuvieron en el terreno de lo lingüístico sin ocuparse de paradigmas difícilmente estructurables como los conceptos ${ }^{31}$. Sigue sin desaparecer, por tanto, la idea de que los tropos $\mathrm{y}$, en particular, la metáfora, son desvíos o traslaciones de significado ${ }^{32}$.

La decantación de la lingüística por el concepto sólo se verifica en la gramática cognitiva ${ }^{33}$. Antecedentes de este giro se pueden encontrar en el ámbito de la propia lingüística y en el de la filosofía. Así, y en cierto modo, la atención singular que estructuralistas como Mathesius ${ }^{34}$ y Jakobson ${ }^{35}-\mathrm{y}$, en general, todos los miembros del Círculo de Praga ${ }^{36}$ - prestan a la función emotiva y apelativa del lenguaje, preludia los estudios posteriores sobre el uso y la significación de las palabras y, desde ahí, sobre el universo conceptual que éstas describen.

Estos estudios también se pueden tener por antecedentes de los trabajos sobre retórica de la conversación, de la cortesía y de las emociones, 
llevados a término por autores como R. Brown y A. Gilman ${ }^{37}$, W. L. Cha$\mathrm{fe}^{38}$, P. Brown y S. Levinson ${ }^{39}$, R. T. Lakoff ${ }^{40}$, C. Caffi y R. W. Janney ${ }^{41}$ o D. Tannen ${ }^{42}$. A través de estos textos se pueden relacionar tropos como la elisión con ciertas implicaciones conversacionales, la ironía o la paradoja con la formulación de ciertos estados de ánimo, y el símil, la perífrasis, la personificación o la hipérbole -por mencionar algunos tropos o figuras- con estrategias comunicativas que influyen en la modalidad y la cortesía de géneros tan dinámicos en la actualidad como el discurso académico, empresarial o político ${ }^{43}$.

El interés de la filosofía por el concepto deriva, como cabe esperar, por ser en él en donde el mundo y la realidad se entrecruzan con el pensamiento y la emoción humanos. Tal vez sea ésta la causa de que haya sido la metáfora el tropo más estudiado ${ }^{44}$, tanto por su trascendencia especial en la formación del lenguaje humano como por su adecuación para explicar los conceptos que el hombre baraja. Esta implicación de lo filosófico en el debate lingüístico hizo que C. Broke-Rose hablara de dos tipos de metáforas: la filosófica, en las que se produciría una transferencia de ideas, y la lingüística, en las que la transferencia queda circunscrita a lexemas y palabras ${ }^{45}$. Esta dicotomía quedará superada cuando la lingüística cognitiva enlace la generación de las ideas con la expresión lingüística de las mismas.

\section{La Metáfora Cognitiva}

La psicolingüística y la lingüística cognitiva surgen y se van desarrollando al socaire de los avances de la psicología cognitiva en áreas de estudio común como los procesos de almacenamiento y transferencia de la información ${ }^{46}$ y los procesos cognitivos que intervienen en el desarrollo de la inteligencia y de las habilidades mentales ${ }^{47}$. Esta nueva perspectiva ha trasvasado el centro de interés de la lingüística a lo conceptual, a la manera de significar de las palabras y a sus valores pragmáticos. Los cognitivistas, por decirlo así, ven la lengua como un recipiente de significados y, por ello, como recipiente de objetos. Por ello, la primera denominación que se dio a esta corriente fue la de gramática de espacios ${ }^{48}$, modificada poco después por la de gramática cognitiva ${ }^{49} \mathrm{y}$, finalmente, la de semántica cognitiva o lingüística cognitiva ${ }^{50}$, que es la denominación más usual en nuestros días ${ }^{51}$. Con estos términos se trataba de poner de relieve que el lenguaje, de naturaleza sustancialmente metafórica, se conforma como una proyección de los espacios humanos, empezando por el del propio cuerpo del hombre, de ahí que sea la metáfora el tropo que ha recibido mayor atención por estos lingüistas ${ }^{52}$. 


\section{Cognición y Retórica}

Entre los antecedentes de los estudios cognitivos aplicados a la metáfora está M. Black, que había postulado que este tropo no podía explicarse en función del referente, sino desde la pragmática, o lo que es lo mismo, desde su uso: semántica y pragmática convergen ${ }^{53}$. En una línea semejante D. Davidson ${ }^{54}$ sostendrá también que la metáfora se fundamenta en la pragmática y, autores como H. P. Grice ${ }^{55}$ y J.R. Searle ${ }^{56}$, en los actos de habla. Con todo, no será hasta 1979 cuando se plantee claramente la corrección de la idea clásica de que la metáfora era propia del lenguaje literario. Lo hizo M. Reddy al afirmar que la metáfora es propia tanto del lenguaje cotidiano como de los lenguajes científicos, porque, antes de ser un obstáculo frente a la claridad y la inambigüedad, es un procedimiento de generación de conceptos ${ }^{57}$. El siguiente paso en este devenir de la gramática cognitiva lo dieron G. Lakoff y M. Johnson ${ }^{58}$, transformados en los auténticos sistematizadores de la teoría cognitiva de la metáfora.

Con ciertos matices, se puede afirmar a modo de resumen que, desde la perspectiva cognitivista, la metáfora es un apareamiento de dos campos conceptuales y no de dos campos semánticos. Por ello hay que distinguir claramente entre metáfora y expresión metafórica, en donde la metáfora se perfila como una red conceptual, mientras que la expresión metafórica sería, por utilizar un tecnicismo generativo, la realización lingüística superficial de la metáfora. De ahí el neologismo mapeo -del inglés mapping- utilizado por los lingüistas cognitivos con el que se pone de manifiesto que la metáfora se produce por la proyección en un territorio conceptual de otro ámbito de conceptos.

A partir de estas investigaciones se han desarrollado interesantes trabajos en el ámbito de la tipología lingüística ${ }^{59}$ y de la lexicogénesis ${ }^{60}$. En concreto, la lexicogénesis postula la existencia de un núcleo básico de conceptos que, por así decir, son el sustrato sobre el que se construyen las diferentes lenguas. Las metáforas son una parte más de ese núcleo básico de conceptos. Se pone así en entredicho la noción saussuriana de la inmotivación del signo lingüístico. La semántica y la pragmática irían, en definitiva, de la mano. El significado no se encuentra en la isla léxica, sino en el entramado conceptual.

Entre las críticas que se hace a este acercamiento es haber dejado al margen la fraseología y las paremias, así como su cierto carácter especulativo ${ }^{61}$. Ambos supuestos son explicables: no todas las cosas pueden estudiarse al mismo tiempo y con la misma profundidad. Es más, la potencialidad de una teoría se debe medir no sólo por lo que estudia, sino -y, sobre todo- por los caminos que deja abiertos para otras investigaciones. 


\section{Hacia Una Retórica Cognitiva}

Si se pretende asentar las bases de una retórica cognitiva, partiendo de la retórica elocutiva afirmada en Occidente desde la Roma del Bajo Imperio, hay que comenzar por redefinir los tropos y las figuras con el fin de enfatizar su faceta de instrumento mental y emocional. Los tropos y figuras ya no serán sólo rasgos que marcan la función poética del lenguaje, sino procesos mentales que dan razón del nacimiento y evolución del lenguaje humano. De este modo quedaría superada la concepción de la elocutio, surgida de enfocar el estudio de tropos y figuras en la palabra, como cosmética del lenguaje, como lujo literario ${ }^{62}$. Se hace preciso, por tanto, centrar el debate en el concepto.

La primera consecuencia de ello es la necesidad de distinguir, como se indicó antes en relación a la metáfora, entre metonimia, ironía o hipérbole -por poner algún ejemplo- y expresiones metonímicas, irónicas o hiperbólicas. Las primeras responden a las tramas o redes conceptuales; las segundas, a la realización lingüística concreta. Por tanto, no sólo la metáfora, como I. A. Richards ${ }^{63}$, o E. Cassirer ${ }^{64}$, M. Black ${ }^{65}$ o P. Ricoeur ${ }^{66}$, es un mecanismo de cognición, sino que lo es todo el conjunto de tropos y figuras. También hay que hacer extensiva a todos los tropos y figuras la afirmación de G. Lakoff de que la metáfora es necesaria para pensar, comprender y actuar ${ }^{67}$. Así, lo mismo que no hay metáforas muertas ${ }^{68}$, tampoco hay figuras ni tropos secluidos en el espacio del mero ornato.

Sin embargo, la bibliografía sobre los aspectos cognitivos de tropos y figuras es escasísima. Destacan dos trabajos firmados, respectivamente, por R. W. Gibbs ${ }^{69}$ y por E. Winner y H. Gardner ${ }^{70}$. En el primero de ellos se sostiene que tropos como la metáfora, la metonimia, la sinécdoque y la ironía forman parte de la experiencia cognoscitiva humana ${ }^{71}$. Por tanto, para entender su significado no sería preciso discernir entre un sentido literal y otro no-literal ${ }^{72}$, porque tropos y figuras forman parte del instrumental del pensamiento humano. En el segundo artículo citado se pasa revista, en concreto, a las relaciones existentes entre metáfora e ironía. La conclusión es clara:

Thus, metaphor functions to describe, to explain something in a particu-

larly apt, memorable, and new way. In contrast, irony functions to show the speaker's evaluative attitude and, as a by-product, to show the kind of involvement ${ }^{73}$.

En consecuencia, la elocutio retórica puede ilustrar los procesos cognitivos que definen la vida cotidiana del ser humano, tales como los neuro-psicológicos, los creativo-científicos o los que definen la identidad cultural. Es un compendio que da cuenta de cómo funciona el pensamiento 


\section{Cognición y Retórica}

y el lenguaje humanos y que, al tiempo, describe la visión de la realidad y del mundo, propia de cada cultura o civilización. No es un catálogo de reglas o normas comunicativas, sino que es el mecanismo básico con el que hombre comprende, explica y manipula el mundo que le rodea. Por ello una elocutio cognoscitiva puede esclarecer el universo ideológico de una sociedad. Tropos y figuras formarían parte, si se nos permite la comparación, del $\mathrm{ADN}$ que identifica una comunidad lingüística. Se integrarían en lo que se ha dado en llamar memes por analogía con genes: si en estos se incluyen todas las potencialidades de cada ser, en aquellos están presentes todas las potencialidades de cada cultura.

En definitiva, tropos y figuras forman parte, por un lado, del conjunto de herramientas mentales y cognoscitivas del individuo y, por otro, de los principios epistemológicos de cada sociedad. Se les puede considerar, además, recipientes de las expectativas ideológicas y emotivas de las diversas comunidades lingüísticas. Su cometido principal no puede ser, centrándonos en el ámbito de los tropos, «la alienación atribuible funcionalmente al ornatus» ${ }^{74}$, sino que son, en síntesis, estructuras cognoscitivas y estructuras sociales ${ }^{75}$.

Para ejemplificar estas afirmaciones pueden estudiarse algunos tropos. La retórica tradicional los agrupa, a grandes rasgos, en dos grandes apartados:

1. Los surgidos por desplazamiento de los límites del contenido de un cuerpo léxico, como la perífrasis, la sinécdoque, la antonomasia o el énfasis.

2. Los que nacen del desplazamiento del contenido fuera del plano conceptual, como la metáfora, la metonimia y la ironía.

De todos ellos, como se ha indicado, es la metáfora el que ha recibido una atención prácticamente exclusiva $\mathrm{y}$, siguiendo su estela, la metonimia y la ironía. Por ello, podemos centrar las conclusiones de este trabajo en los agrupados en el primer grupo, definidos por $\mathrm{H}$. Lausberg como sigue $^{76}$ :

- Perífrasis: «es la sustitución de un verbum proprium (que existe o no en la lengua) por un conjunto de datos que tienen como contenido la sustancia y los rasgos característicos de la cosa indicada».

- Sinécdoque: «consiste en un desplazamiento de la denominación de la cosa indicada dentro del plano del contenido conceptual, pudiendo la denominación trópica traspasar los límites del contenido conceptual (locus a maiore ad minus) o no alcanzarlos (locus a minore ad maius): hay, pues, una sinécdoque de lo amplio y una sinécdoque de lo reducido». 
- Antonomasia: «es una variante de la perífrasis y de la sinécdoque empleada en los nombre propios. (...) La antonomasia propia consiste en la sustitución de un nombre propio por una perífrasis o por un apelativo. (...) La antonomasia vossiana consiste en la sustitución de un apelativo por un nombre propio».

- Énfasis: «designa un rasgo característico mediante un concepto que contiene a este rasgo como tal, pero sin expresarlo».

Puede inferirse de estas definiciones que los tropos mencionados, en última instancia, describen procesos mentales cotidianos en los seres humanos. La perífrasis no es una simple sustitución del 'verbum propium por un conjunto de datos' con finalidad de ornato. Antes bien, es un procedimiento por el que el hombre explica, matiza o caracteriza habitualmente su universo cognitivo. Aún más, junto a la comparación, es el mecanismo definitorio por excelencia. Así, llamar a la primavera estación florida no es simplemente un modo de evitar el término primavera en aras de un supuesto embellecimiento del discurso: es, más bien, la forma habitual con la que el hombre define la primavera como la época de la mayor eclosión floral del año. Esa perífrasis revela uno de los rasgos que el hombre pone en la primavera. En consecuencia, todas las cosas poseen una naturaleza humana, es decir, una definición que depende, más allá de su realidad, de la realidad que el hombre le impone con su lenguaje. El lenguaje es el barro con el que el hombre da vida a lo que le rodea. Las perífrasis son, en este sentido, señas que descubren la realidad cognoscitiva de las cosas, son indicios de los valores que el hombre atribuye a las cosas de su entorno.

Estas afirmaciones sirven para el resto de los tropos citados. En concreto, el tropo denominado sinécdoque muestra cómo el hombre, para comprender las cosas, observa el mundo como conjunto de estructuras que se engloban unas en otras. El hombre perfila, por así decir, los límites difusos de la realidad, de la misma manera que, al contemplar en un papel el dibujo incompleto de un círculo, le llamará círculo obviando la falta de una porción de circunferencia. Así, cuando dice Sevilla merece unas Olimpíadas no lo hace porque quiera causar una extrañeza estética en el que oye la frase, sino porque en el universo cognoscitivo humano la ciudad es el ámbito propio de la civilización. Esta sinécdoque se basa en la continuidad que se establece entre hombre y ciudad: el hombre es un animal social; la ciudad es el alterego de la sociedad. La sinécdoque construye una idea de hombre y una idea de ciudad.

El mismo fenómeno es aislable en las antonomasias: se llama Don Juan a un conquistador, el filósofo a Aristóteles o el que todo lo ve a Dios, 


\section{Cognición y Retórica}

porque los rasgos que se realzan en la antonomasia constituye la característica más relevante que el hombre atribuye a los objetos o personas mencionados. Sin ese rasgo, el llamado por la retórica tradicional término propio no existiría, porque no formaría parte del universo conceptual humano. La antonomasia es un tropo, por otro lado, que permite notar las marcas definitorias de una determinada cultura y descubrir, entre otras distinciones, sus tabúes.

Si la antonomasia es un tropo relacionado, sobre todo, con la esfera socio-cultural, el énfasis lo está con la emocional. El énfasis no es una cuestión puramente lingüística, sino que indica la vinculación emotiva del hombre con los conceptos que maneja. Decir eso es un hombre a un señor que llora desconsoladamente la muerte de su esposa, pero que afronta con serenidad y simultáneamente la obligación de criar a sus hijos, es una exteriorización de la admiración, la solidaridad y el respeto que el que pronuncia esa frase siente por la persona aludida. Exterioriza, igualmente, la jerarquía de sus valores personales que, en un porcentaje muy elevado, mostrará también la jerarquía de valores de la sociedad en la que se integra.

En consecuencia, el ser humano piensa metaforizando, como ha puesto de relieve la psicología y la lingüística cognitivas, pero también perifraseando, sinecdoquizando, antonomasiando o enfatizando. Por tanto, como afirma D. Parente, el concepto de lenguaje literal es un obstáculo para la investigación de la metáfora ${ }^{77}$. Habría que añadir, que, también, para la investigación general sobre el lenguaje humano. Los tropos y figuras son los procedimientos con los que el hombre pasa de lo experiencial a lo verbal, de las sensaciones a las palabras. Son bisturíes con los que el hombre disecciona la naturaleza. Además, son los utensilios que transforman lo individual en social y lo social en cultural, ya que la descripción del mundo que ofrece toda lengua es, ineludiblemente, colectiva.

De esa descripción, y en ese orden, nace la explicación. Primero se describe y luego se comprende, y éste es el valor cognitivo fundamental de tropos y figuras: son fórmulas de descripción que contribuyen a la formación del universo cognoscitivo humano. Sólo entonces tropos y figuras pueden servir para embellecer los discursos. Podría afirmarse que el hombre embellece el mundo al comprenderlo o, si se quiere, que embellecer el mundo significa comprenderlo. El hombre comprende a través de la palabra, de una palabra que tiene la virtualidad de mostrar los valores que el hombre selecciona del mundo. Los tropos y figuras, en definitiva, son los criterios de selección que el ser humano utiliza en su descripción y comprensión del mundo. 
Notas

1 Plato Phd. 277b-c.

2 Vd. Gorgias, Protágoras, Sofista o Fedro.

3 ISOC. Nic. 7-9.

4 ISOC. Antid. 253-4.

5 CIC. De orat. I 6 20s.

6 Takatura, A. (1971): Aristotle's Theory of Practical Cognition. The Hague: Martinus Nijhoff, 56-65.

7 ARIST. Rhet. 1354a.

8 ARIST. Pol. $1278 \mathrm{~b} 19$.

9 ARIST. Rhet. 1356a.

10 CIC. De orat. $132 \mathrm{~s}$ : “Hoc enim uno praestamus vel maxime feris, quod colloquimur inter nos, et quod exprimere dicendo sensa possumus. Quam ob rem quis hoc non iure miretur, summeque in eo elaborandum esse arbitretur, ut, quo uno homines maxime bestiis praestent, in hoc hominibus ipsis antecellat? ".

11 CIC. Inv. I 2-3; QUINT. I 16 12-5; II 16 9-10; II 20 9; III 21.

12 CIC. Brut. 40.

13 CIC. De orat. 1 146: "Verum ego hanc intellego esse in praeceptis omnibus, non ut ea secuti oratores, eloquentiae laudem sint adepti, sed, quae sua sponte homines eloquentes facerent, ea quosdam observasse atque collegisse; sic esse non eloquentiam ex artificio, sed artificium ex eloquentia natum».

14 QUINT. I 45.

15 QUINT. 1Pr. 21s.

16 QUINT. 8Pr. 15s.

17 Eisenhut, W. (1974): Einführung in die antike Rhetorik und ihre Geschichte. Darmstadt: Bayrischen Schulbuch-Verlag, 9. Kennedy, G.A. (1980): Classical Rhetoric and Its Christian and Secular Tradition from Ancient to Modern Times. Chape Hill: University of North Calorina Press, 5. Siles, J. (1983): Introducción a la lengua y la literatura latinas. Madrid: Istmo, 213s. Cole, T. (1996): Le origini della retorica", QUCC 23/3, 721.

18 TAC. Dial. 311.

19 TAC. Dial. $262 \mathrm{~s}$.

20 TAC. Dial. 282.

21 TAC. Dial. 402.

${ }^{22}$ Lausberg, H. (19932): Elementos de retórica literaria. Introducción al estudio de la filología clásica, románica, inglesa y alemana. Madrid: Gredos, 61.

${ }_{23}$ Du Marsais, C.C. (1730): Traité des tropes. Paris: Veuve de J.-B. Brocas.

24 Humboldt, W. von (1825): “Über das Entstehen der grammatischen Formen und ihren Einfluß auf die Ideenentwicklung». Abhandlungen der historisch-philologischen Klasse der Königlichen Akademie der Wissenschaften zu Berlin. Aus den Jahren 1822-23: 401-430.

25 Biese, A. (1893): Philosophie des Metaphorischen. Hamburg-Leipzig: Voss.

${ }^{26}$ Nietzsche, F. (1990): Sobre verdad y mentira en sentido extramoral. Madrid: Tecnos.

27 Cassirer, P. (1946): Language and Myth. Dover: Harper and Brothers.

28 Croce, B. (1902): Estetica come scienza dell'expressione e linguistica generale. Bari: Laterza, I, IX. 


\section{Cognición y Retórica}

29 ARIST. Rhet. 1410b.

${ }^{30}$ Konrad, J. (1958): Étude sur la métaphore. Paris: Vrin. Grupo $\mu$ (1970): Rhétorique générale. París: Larousse. Henry, A. (1971): Métonimie et métaphore. Paris: Klincksieck. Tato, J.-L. (1975): Semántica de la metáfora. Alicante: Diputación provincial. Le Guern, M. (1976): La metáfora y la metonimia. Madrid: Cátedra. Normand, C. (1976): Métaphore et concept. Bruxelles: Presses universitaires de France. Grupo $\mu$ (1977): Rhétorique de la poésie. Bruxelles: Complexe. Aarts, J. M. G. - Calbert, J. P. (1979): Metaphor and Non-Metaphor. The Semantics of Adjective-Noun Combinations. Tübingen: Max Niemeyer.

31 Otros estructuralistas superarían esta barrera apostando por un acceso interdisciplinar a los textos: Van Dijk, T. A. (1983): La ciencia del texto. Barcelona - Buenos Aires: Paidós, 20.

32 Estas ideas se presentan bajo nuevo aspecto en otros autores, por ejemplo, D. Davidson califica el lenguaje metafórico de insinuante (Davidson, D. (1995): "Qué significan las metáforas", De la verdad y de la interpretación: Barcelona: Gedisa); H.P. Grice, de transgresión de las máximas conversacionales (Grice, H.P. (1991): «Lógica y conversación". En Valdés Villanueva, L. [Ed.]: La búsqueda del significado. Madrid. Tecnos, 511$530)$; J. Searle, de discordancias entre el significado del hablante y el enunciado literal que sólo se unifica en la cadena comunicativa (Searle, J. (1990): «Metaphor». En Martinich, A. [Ed.]: The Philosophy of Language. Oxford: Oxford University Press, 408-29).

${ }^{33}$ Sobre este tema destaca, en el terreno de la filología clásica, el siguiente título: García Jurado, F. (2003): Introducción a la semántica latina. De la semántica tradicional al cognitivismo. Madrid: Universidad Complutense.

${ }^{34}$ Mathesius, V. (1911): «On the potentiality of the phenomena of language» y (1928) "On the linguistic characterology of modern English", en Vachek, J. [Ed.] (1964): A Prague School Reader in Linguistics. Indiana: University of Indiana Press.

35 Jakobson, R., Halle, M. (1973): Fundamentos del lenguaje. Madrid: Ayuso. Jakobson, R. $\left(1983^{2}\right)$ : Lingüística y poética. Madrid: Cátedra.

36 Vachek, J. [Ed.] (1964): A Prague School Reader in Linguistics. Indiana: University of Indiana Press.

37 Brown, R., Gilman, A. (1960): «The pronouns of power and solidarity». En Sebeok, T.A. [Ed.]: Style in Language. Cambridge, Mass: MIT Press, 253-276.

${ }^{38}$ Chafe, W.L. [Ed.] (1980): The Pear Stories: Cognitive, Cultural and Linguistic As. pects of Narrative Production. Norwood, NJ: Ablex; id. (1982): "Integration and involvement in speaking, writing and oral literature». En Tannen, D. [Ed.] Spoken and Written Language: Exploring Orality and Literacy. Norwood, NJ: Ablex. Chafe, W.L., Nichols, J. [Eds.] (1986): Evidentiality: The Linguistic Coding of Epistemology. Norwood, NJ: Ablex.

39 Brown, P., Levinson, S. (1987): Politeness: Some Universals in Language Usage. Cambridge: Cambridge University Press.

${ }^{40}$ Lakoff, R. T. (1990): Talking Power: The Politics of Language in our Lives. New York: Basic Books.

${ }^{41}$ Caffi C., Janney R. W. (1994): “Toward a pragmatics of emotive communication", Journal of Pragmatics, 22: 325-373.

${ }^{42}$ Tannen, D. (1984): Conversational Style: Analysing Talk among Friends. Norwood, NJ: Ablex; id. (1987): "Repetition in conversation: Towards a poetics of talk. Language, 63/3: 574-605; id. (1989): Talking voices. Repetition, Dialogue and Imagery in Conversational Discourse. Cambridge: Cambridge University Press.

43 Giménez Moreno, R. (2000): La repetición lingüistica en el género de la clase magis tral: el inglés académico oral en el ámbito de las ciencias sociales. Tesis doctoral inédita. 


\section{Marco Antonio Coronel Ramos, Rosa Giménez Moreno}

44 Shibles, A. (1971): Metaphor: An Annotated Bibliography and History. Bloomington, Ind.: John Benjamins. Radman, Z. [Ed.] (1995): From a Metaphorical Point of View A Multidisciplinary Approach to the Cognitive Content of Metaphor. Berlin - New York: Walter de Gruyter. En este volumen destacan las dos aportaciones siguientes: MacCormac, E. R.:«Neuronal Processes of Creative Metaphors», 149-164; y Radman, Z.: «How to Make Our Ideas Clear with Metaphors", 225-256.

45 Brooke-Rose, C. (1958): A Grammar of metaphor. London: Secker and Warburg, 3.

46 Atkinson, R.C., Shiffrin, R.M. (1968): «Human memory: A proposed system and its control processes». En Spence, K.W., Spence, J.T. [Eds.] The Psychology of Learning and Motivation: Advances in Research and Theory. New York: Academic Press. Craik, F.I.M., Lockhart, R.S. (1972): "Levels of processing: A framework for memory research». Journal of Verbal Learning and Verbal Behaviour, 11: 671-684. Sternberg, S. (1966): «High-speed scanning in human memory». Science, 153: 652-654. id. (1969): "The discovery of processing stages». Acta Psychologica, 30: 276-315.

47 Spearman, C. (1904): "General intelligence objectively determined and measured». American Journal of Psychology, 15: 201-293. Terman, L.M. (1921): «In Symposium: Intelligence and its measurement». Journal of Educational Psychology, 12: 127133. Piaget, J. (1952): The Origins of Intelligence in Children. New York: Internacional Universities Press. Wechsler, D. (1939): The Measurement of Adult Intelligence. Baltimore: Williams and Wilkins; id. (1958) The Measurement and Appraisal of Adult Intelligence. Baltimore: Williams and Wilkins. Guilford, J.P. (1959): "Three faces of intellect» American Psychologist, 14: 469-479. Guilford, J.P. (1967): The Nature of Human Intelligence. New York: McGrawHill. Sternberg, R.J. (1979): "Stalking the IQ quark» Psychology Today, 13/4: 27-41. Sternberg, R.J. (1982): “Who's intelligent?» Psychology Today, 16/4: 3040 .

48 Langacker, R. (1979): «Grammar as image», Linguistic Notes from La jolla 6: 88126.

49 Langacker, R. (1986): An Introduction to Cognitive Grammar. San Diego: University of California; id. (1987): Foundations of Cognitive Grammar: Theoretical Prerequisites. Vol. 1. Stanford: Stanford University Press.

${ }^{50}$ Lakoff, G. (1986): “Cognitive Semantics». Berkeley Cognitive Science Report, 36

51 Cuenca, M. J., Hilferty, J. (1999): Introducción a la lingüistica cognitiva. Barcelona: Ariel. Luque Durán, J. de D., Pamies Bertrán, N, A., Manjón Pozas, F. J. (2002): Nuevas Tendencias en la investigación lingüística. Granada: Método.

52 Black, M. (1962): “Metaphor». En Models and Metaphors. Ithaca: Cornell University Press. Davidson, D. (1979): “What Metaphors Mean». En Sacks, S. [Ed.], On Metaphor. Chicago: The University of Chicago Press. Ricoeur, P. (1979): «The metaphorical process as cognition, imagination, and feeling». En Sacks, S. [Ed.], On Metaphor. Chicago: The University of Chicago Press. Ortony, A. [Ed] (1979): Metaphor and Thought. Cambridge: Cambridge University Press. Lakoff, G., Johnson, M. (1980): Metaphors We Live By. Chicago: The unviersity of Chicago Press. Rivano, J. (1986): Perspectivas sobre la metáfora. Santiago de Chile: Editorial universitaria. Feder Kittay, E. (19892): Metaphor. Its Cognitive Force and Linguistic Structure. Oxford: Clarendon Press. Sternberg, R. J. (1990): Metaphors of Mind. Conceptions of the Nature of Intelligence. Cambridge: Cambridge University Press. Fernández, J. W. [Ed.] (1991): Beyond Metaphor. The Theory of Tropes in Antropology. Standford: Standford University Press. Indurkhya, B. (1992): $M e-$ taphor and Cognition. An Interactionist Approach. Dordrecht - Boston - London Kluwer Academic Publishers. Manjali, F. D. [Ed.] (1993): Language and Cognition. New Dehli: 
Bahri publications. Coorebyter, V. De (1994): Rhétoriques de la science. Paris: Puf. Oteen, G. (1994): Understanding Metaphor in Literature. An Empirical Approach. London New York: Longman. Fernández, J. [Ed.] (1994): Beyond Metaphor: the Theory of Tropes in Anthropology. Standford: Standford University Press. Debatin, B., Jackson, T. R., Steuer, D. [Eds.] (1996): Metaphor and Rational Discourse. Tübingen: Max Niemeyer. Pérez Rull, J.C. (1998): Semántica cognitiva intercultural. Granada: Método. Allwood, J., Gärdenfors, P. (1999): Cognitive Semantics. Amsterdam, John Benjamins. Albertazizi, A. (2000): Meaning and Cognition. Amsterdam - Philadelphia: John Benjamins. Kövecses, Z. (2002): Metaphor. A practical Introduction. Oxford, Oxford University Press. Barcelona, A. [Ed.] (2003): Metaphor and Metonimy at the Crossroads. A Cognitive Perspective. Berlin - New York: Mouton de Gruyter.

53 Black, M. (1962): «Metaphor». En Models and Metaphors. Ithaca: Cornell University Press.

54 Davidson, D. (1979): «The inscrutability of Reference». Southwestern Journal of Philosophy, 10: 7-19. Se reimprimió en 1984: Inquiries into truth and interpretation. Oxford: Clarendon Press.

55 Grice, H. P. (1975): «Logic and conversation». En Davidson, D., Harman, G. [Eds.]: The Logic of Grammar. Encino, NM: Dickenson, 64-75.

56 Searle, J. R. (1979): Expression and Meaning. Cambridge: Cambridge University Press.

57 Reddy, M. (1979): "The conduit metaphor. A case of frame conflict in our language about language». En Ortony, A. [Ed.]: Metaphor and Thought. Cambridge: Cambridge University Press.

58 Lakoff, G., Johnson, M. (1980): Metaphors We Live By. Chicago: The unviersity of Chicago Press. Existe traducción española: $\left(1995^{3}\right)$ : Metáforas de la vida cotidiana. Madrid: Cátedra.

59 Wierzbicka, A. (1988): The Semantics of Grammar. Amsterdam: John Benjamins; Id. (1993a): «La quête des primitifs sémantiques: 1965-1992». Langue française, 98: 9-13; Id. (1993b): "Les universaux de la grammaire». Langue française, 98: 107-120; Id. (1996): Semantics: Primes and Universals. Oxford: Oxford University Press.

${ }^{60}$ Luque Durán, J. de D., Manjón Pozas, F. J. (1998): Introducción a la historia de la tipología lingüística. Granada: Granada Lingüística y Método Ediciones. Luque Durán, J. de D. (2001): Aspectos universales y particulares del léxico de las lenguas del mundo. Granada: Granada Lingüística.

${ }^{61}$ Iñesta Mena, E. M., Palies Bertrán, A. (2002): Fraseología y metáfora: aspectos tipológicos y cognitivos. Granada: Granada lingüística, 5.

${ }^{62}$ Ricoeur, P. (1975): La métaphore vive. Paris : Éditions du Seuil, 64-5: «Le déclin de la rhétorique résulte d'une erreur initiale qui affecte la théorie même des tropes, indépendamment de la place accordée à la tropologie dans le champ rhétorique. Cette erreur initiale tient à la dictature du mot dans la théorie de la signification. De cette erreur on n'aperçoit que l'effet le plus lointain: la réduction de la métaphore à un simple ornement. Entre le point de départ -le primat du mot- et le point d'arrivée -la métaphore comme ornement-, se dóploi toute une série de postulats qui, de proche en proche, rendent solidaires la théorie initiale de la signification, axée sur la dénomination, et une théorie purement ornementale du trope qui avère finalement la futilité d'une discipline que Platon avait déjà rangée du même côté que la cosmétique».

${ }^{63}$ Richards, I. A. (1936): The Philosophy of Rhetoric. New York: Oxford University Press. 


\section{Marco Antonio Coronel Ramos, Rosa Giménez Moreno}

64 Cassirer, P. (1946): Language and Myth. Dover: Harper and Brothers.

65 Black, M. (1962): “Metaphor». En Models and Metaphors. Ithaca: Cornell University Press. Davidson, D. (1979): “What Metaphors Mean». En Sacks, S. [Ed.], On Metaphor. Chicago: The University of Chicago Press.

${ }_{66}$ Ricoeur, P. (1979): «The metaphorical process as cognition, imagination, and feeling. En Sacks, S. [Ed.], On Metaphor. Chicago: The University of Chicago Press.

67 Lakoff, G., Johnson, M. (1980): Metaphors We Live By. Chicago: The university of Chicago Press, 3.

68 Ungerer, F., Schmid, H.-J (1996): An Introduction to Cognitive Linguistics. London: Longman: 118.

69 Raymond W. Gibbs, JR., (1979): «Process and Products in making sense of tropes». En Ortony, A. [Ed.]: Metaphor and Thought. Cambridge: Cambridge University Press, 252-276.

70 Winner, E., Gardiner, H. (1979): «Metaphor and irony: two levels of understanding». En Ortony, A. [Ed.]: Metaphor and Thought. Cambridge: Cambridge University Press, 425-443.

71 Raymond W. Gibbs, JR., (1979): «Process and Products in making sense of tropes». En Ortony, A. [Ed.]: Metaphor and Thought. Cambridge: Cambridge University Press, 253.

72 Raymond W. Gibbs, JR., (1979): "Process and Products in making sense of tropes". En Ortony, A. [Ed.]: Metaphor and Thought. Cambridge: Cambridge University Press, 275.

73 Winner, E., Gardiner, H. (1979): "Metaphor and Irony: two levels of understanding». En Ortony, A. [Ed.]: Metaphor and Thought. Cambridge: Cambridge University Press, 429.

${ }^{74}$ Lausberg, H. (19932): Elementos de retórica literaria. Introducción al estudio de la filología clásica, románica, inglesa y alemana. Madrid: Gredos, 95.

75 Mailloux, S. (1989): Rhetorical Power. Ithaca: Cornel University Press. Atkinson, D. (2002): "Toward a socio-cognitive approach to second language adquisition", Modern Language Journal, 86: 525-545. Luke, T. W. (2004), «Megametaphorics: Re-reading Globalization, Sustainability and Virtualization as Rhetorics of World Politics». Bajado de la página web http: / / www.cddc.vt.edu/tim/tims / 684.PDF.

${ }^{76}$ Lausberg, H. (19932): Elementos de retórica literaria. Introducción al estudio de la filología clásica, románica, inglesa y alemana. Madrid: Gredos, 107-113.

77 Parente, D. (2002): Márgenes del lenguaje. Metáfora y conocimiento. Mar del Plata: Ediciones Suárez, 120. 